\title{
Review of Ceramic Coating on Mild Steel Methods, Applications and Opportunities
}

\author{
Pavan C $\mathbf{M}^{* 1}$ and Dr. Narendra Babu B $\mathbf{R}^{2}$ \\ ${ }^{1}$ Assistant Professor, Department of Mechanical Engineering, GMIT, Bharathinagara. \\ Mandya, Karnataka, \\ ${ }^{2}$ Professor \& Head, Department of Mechanical Engineering, VVIET, Mysore \\ Karnataka, \\ India
}

\begin{abstract}
Ceramic coatings possess good thermal and electrical properties and they are resistant to oxidation and erosion in high temperature environments. This property is a very important factor in the applications such as pipelines, castings and automotive industry. Ceramic and metallic coatings for wear and corrosion protection of engineered structures applied by thermal spraying techniques have become a mainstay of surface engineering. This paper summarizes the recent technological advancement of ceramic coatings on Mild steel and also summarizes the current research, advanced ceramic coating materials and surface coating methods. New applications which have emerged from the past few years are described in this paper.

Plasma spraying will be carried out using the atmospheric plasma spray system. Input DC power to the plasma torch will vary from $10 \mathrm{~kW}$ to $20 \mathrm{~kW}$ by controlling the arc current. In order to study the in-flight reaction of ceramic coating, a set of spheroidization experiments is carried out under identical conditions.
\end{abstract}

Key Words: Ceramic Coatings, Mild Steel, Applications, Types of coating.

\section{INTRODUCTION}

The Ceramic coatings on metallic materials have shown a significant improvement since 1970. With developing technology, metals and metallic alloys require high performance in different environments. From 1980, the ceramic coatings have been applied in adiabatic engines [1]. First of all gas turbine wings were used in this area, and then piston, cylinder lining, valve, piston crown surface were used for ceramic coatings [2]. A number of metal ceramic combinations possessed unusual properties. Generally, carbides like silicon carbide, tungsten carbide are used as dispersiods where hardness and wear resistance are the major requirements. But oxides like $\mathrm{TiO}_{2}, \mathrm{SiO}_{2}, \mathrm{Al}_{2} \mathrm{O}_{3}$, etc., are used where resistance to oxidation even at high temperatures is required along with hardness and wear improvement over conventional nickel deposits [7].

Ceramic coatings have been extensively employed in the surface modification field during the last decades due to their excellent properties [3]. The coating of metal surfaces with a thin ceramic layer has always been a useful means to enhance the mechanical performance of metallic substrates [4]. Surface treatments like ultrasonic cleaning, acid dipping, mechanical and electro chemical polishing, thermal treatment, laser surface melting and plasma exposure are the most commonly used surface treatment methods [5].

Ceramic coatings are mainly used for the protection of base alloys against hot corrosion and oxidation and also for the minimization of wear damage. Another function of ceramic coatings is to reduce the base metal temperature in the case of thermal barrier coatings [6]. Ceramic materials have many advanced properties such as heat resistance, corrosion resistance, wear resistance and electrical insulation. At present, there exists a variety of ceramic coating methods for protective application ceramic coatings. 


\section{RECENT WIDER USE OF CERAMIC MATERIALS}

Ceramic materials are the emerging ideal materials for a wide range of engineering applications such as cutting tools, engines, turbines, space vehicles and biomedical applications due to their superior properties when compared to traditional ceramics. The properties of advanced ceramics mainly differ from those of traditional ceramic materials in their processing, composition and microstructure. Therefore, in order to get a better understanding of advanced ceramic materials and further develop them for a particular engineering application, extensive research must be carried out for evaluating the micro structural, mechanical, electrical, optical and biomedical properties [8].

\subsection{Ceramics for Turbine Applications}

Ceramic materials have many potential advantages in turbine applications. However, it is not feasible to produce a fully dense ceramic turbine engine and hence there is a requirement for the design and manufacture of metal-ceramic bonds. One major obstacle to the use of ceramic materials in turbine applications is the mismatch in coefficient of thermal expansion (CTE) between ceramics and metals. In service, thermal cycling could generate excessive strain at the metal/ceramic interface, possibly enough to cause catastrophic failure of the ceramic. Therefore there is a need to address the various methods for joining ceramic materials such as silicon nitride, to high temperature metals such as nickel alloys. A successful joint design and vacuum brazing procedure have been developed and optimised, based on a mechanically flexible metal interlayer being introduced between the metal and the ceramic. This accommodates the difference in CTE which causes strain within the joint. The difficulty of wetting the ceramic was overcome by the use of an active metal braze alloy or a surface wetting agent. Joint design was studied by use of Finite Element Analysis to generate design information on the predicted life time of the components [9].

\subsection{Thermal and Environmental Barrier Coatings}

Introducing advanced ceramic components into gas turbines increase their operating temperatures, leading to increased efficiency and reduced environmental impact. However, these silicon-based ceramics are susceptible to hot-corrosion and recession in the presence of hot corrosive gases and water vapor at high velocities. This necessitates the use of environmental barrier coatings (EBCs) that are themselves resistant to the aggressive combustion atmospheres, and also act as diffusion barriers that prevent harmful gas-phase components from reaching the ceramic substrates. Further increase in operating temperatures require the use of thermal barrier coatings (TBCs) that are poor thermal conductors and allow for a significant temperature drop across the coatings, thereby letting the substrate to operate at temperatures significantly lower than that of the combustion temperature. Deposition, structure and properties of EBCs on Si-based ceramics as well as EBC/TBC coating systems were considered for the CTE match and lack of harmful chemical interactions at the interfaces, effective thermal conductivity of the TBC and the hot-corrosion and recession resistance of the EBC were considered for the CTE mismatch [10].

\section{RECENT USE OF SURFACE COATINGS}

Applications of surface coatings in sports technology, aeronautic and transport industries, chemical and petroleum industries, food, mining and the electronics industries are discussed. Recently, surface coatings have been utilized increasingly in some specialized areas. Such applications include thermal sprayed coatings in the sports industry (horses hooves, clothing, golfing, swimming), biomedical/ orthopedics (e.g. hydroxyl apatite), dentistry, cancer therapy, art industry (e.g. glass colorings and enameling) and bronze applications [11]. Surface coatings provide a wide range of functions to modify the properties of the components. Typical coatings include pure metals and alloys, nitrides, carbides, Diamond like Carbon (DLC), decorative coatings and thermal barrier coatings. Modern cutting applications cannot be accomplished without protecting the tools with a thin resistant coating. The applications include high speed cutting, hard machining of high hardness materials, dry cutting and cutting of materials such as Titanium, AlSi alloy or other non-ferrous abrasive materials that are difficult to cut. The coatings deposited on the tool surface normally have a thickness of several microns. They enhance wear resistance at the cutting edge and reduce diffusion and friction [11]. Surface engineering contributes very significantly in the transport industry. Approximately $6 \%$ of the cost for manufacturing engines and transmissions are involved in coating technologies. Surface coatings generally have three major categories of applications in the transport industry, namely the power units, vehicle components and fixed permanent structures. Engineering coatings have a number of applications in power generation units, such as diesel engines and power transmission systems. Surface coatings have a function of preventing the power units from erosion and wear. Some vehicle components such as suspension and brakes are coated with thermally sprayed coatings to improve wear resistance, and therefore extend the service life. Epoxy-based polymer coatings are applied to the exposed areas such as wheel arches and bumpers. They are also used as a body coat on some vehicles to increase the abrasion and corrosion resistance. Polymer coatings also help to reduce the noise levels. Another application of surface coatings is for fixed structures such as bridges and oil rigs to combat saltwater corrosion and sand abrasion problems [11]. 


\section{RECENTLY USED SURFACE COATING METHODS}

The following section describes some of the Surface Coating Methods which have been recently used.

\subsection{Plasma Sprayed Ceramic Coatings.}

Ceramic coatings can be readily formed employing a wide variety of techniques (e.g. sputtering, electron-beam deposition). The technique being used since the middle of previous century, to form metal alloys, ceramic and cermets coatings on a range of metallic substrates. These types of coatings mostly greater than $50 \mu \mathrm{m}$ in thickness are used for varieties of engineering applications to realize enhances, wear/erosion and corrosion resistance of thermal barriers, electrical magnetic components and so on.

Plasma spraying technique has been playing a significant role in depositing a variety of ceramic materials on conventional metallic substrates. These coatings are generally employed to realize enhances wear resistance of abatable seals as well as thermal barriers, thus permitting hot sections of gas turbine engines to function at increased operating temperatures in aircraft industries. Plasma sprayed refractory ceramic coatings are also used in handling liquid metals and in electrically insulated metal substrates in the automotive electronics industry.

A number of inter dependent parameters are found to describe the characteristics of the plasma sprayed ceramic coating process. Some of them are gas type, pressure and flow rate, spray distance to cite a few. The physical features of the feed stock powder appear to influence the quality of the coating. Particle size, shape and its distribution and the level of chemical uniformity of the constituents in a mixed oxide are the parameters but to be neglected in this analysis. Particle size influences the melt ability whereas its shape determines the extent of flow ability of the powder into the flame.

The microstructure and phase distribution of plasma sprayed coatings are dissimilar in composition with that of the substrate. Material properties of the coating such as thermal diffusivity, mechanical strength in tension and shear and wear characteristics are found to be different in comparison with that of bulk material [12].

\subsection{Plasma Spray Process}

Plasma spraying is a material processing technique which uses the energy of an electric arc and gases to generate a plasma beam capable of melting and depositing metallic and non-metallic materials on a substrate. This technique has been used to develop protective coatings of ceramics, alloys and composites to enhance the surface properties of critical components operating in severe environment. In conventional plasma spraying, an arc is created between a rod/stick type throated tungsten cathode and a nozzle type copper anode (both water cooled).

Plasma generating gas is forced to pass through the annular space between the electrodes. While passing through the arc, the gas undergoes dissociation and/or ionization in the high temperature environment resulting plasma. The ionization is achieved by collision of electrons of the arc with the neutral molecules of the gas. The plasma protrudes out of the electrode encasement in the form of a jet. The material to be coated is introduced into the plasma jet in powder form in metered quantity by means of a carrier gas. The powder particles, as they enter the plasma jet, are heated and melted and the molten droplets absorb the momentum of the expanding gas and are accelerated to a very high velocities (exceeding $100 \mathrm{~m} / \mathrm{s}$ ). As these molten droplets strike the substrate surface, they flatten and get anchored to the surface irregularities to form an adherent coating. The coating builds up layer by layer. Figure 4.1 shows the Gun design for plasma spraying process.

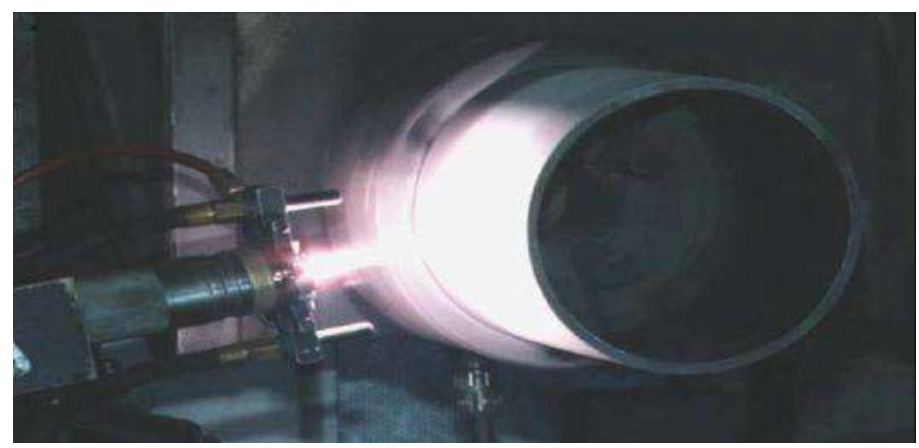

Fig4.1: Plasma Spray Gun

\subsection{High Velocity Oxy-Fuel (HVOF)}

The high velocity oxy-fuel (HVOF) has extended the range of thermal spray applications. HVOF utilizes the combustion of gases, such as hydrogen or a liquid fuel such as kerosene. A mixture of process gases is injected into the combustion chamber of a torch at high pressure and ignited to produce the flame. The process creates a very high velocity which is used to propel the 
particles at near supersonic speeds before impacting onto the substrate and producing a coating. HVOF is designed to give high levels of coating density and adhesion to a substrate.

Since the temperature of the flame is about $3000^{\circ} \mathrm{C}$, HVOF thermal spraying is preferred for spraying tungsten carbide and/or corrosion-resistant carbides, alloy of hast alloy, tribo alloy and inconel. Due to high kinetic energy and low thermal energy of hydrogen, HVOF can produce high bond strengths, extremely high coating density and low oxide content. Figure.4.2 shows a typical gun design and HVOF coating onto substrate.

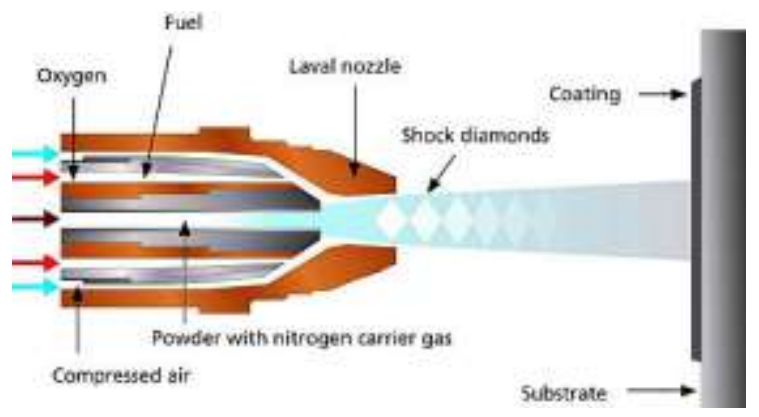

Fig.4.2: Gun Design of HVOF

\section{ADVANCED COATINGS}

So far we have discussed various methods of coating substrates for their use in corrosion protection applications. Although, many of the above methods are in practice, they are not perfect and have several limitations. PVD methods are good but usually have a poor mechanical bond and the thickness is often very small. The method requires a vacuum, and coating of large or intricate parts is difficult. Diffusion coatings such as CVD, pack and slurry are very common and form a good metallurgical bond but because of high substrate temperature, the bulk properties are affected because of a change in the microstructure as a result of heating. Moreover the CVD method is used only for a limited number of coatings and the method becomes complicated if alloy coatings or ceramic coatings using a reactive pack are used. Thermal spray coatings are perhaps being used extensively these days because they are easy to apply, fast and can be made available at the site, however high porosity, non-uniform surface and mechanical bonding with the substrate, often limit their use in several aggressive environments. The recent Development of LPPS and vacuum plasma has to some extent overcome these problems but the size of the specimen is limited by the vacuum chamber, and specimen movement has to be controlled by sophisticated maneuvering from the outside. Thus new methods which are more universal and do not require vacuum are very much required. One of the methods is laser surface alloying.

\subsection{Laser Surface Alloying}

Laser surface alloying uses a laser beam as the heat source. Special properties of the laser beam, such as its beam directionality, high intensity and high spatial resolution make it an excellent heat source. It heats a specific area very fast followed by faster cooling resulting in a novel microstructure. The desired material can either be added simultaneously along with laser irradiation or laser irradiation is carried out on the surface where the material has already been placed by some of the coatings discussed above. Several lasers are now available but $\mathrm{CO}_{2}$ and $\mathrm{Nd}$ :Yag lasers are the two which are mainly used for laser surface processing.

\section{CERAMIC COATING APPLICATIONS}

\subsection{Heat resistant Ceramic Coatings for Gas Turbines}

The operating temperature of gas turbines in the 1990s and later has been notably high in order to achieve high-efficiency powergenerating plants by combining these gas turbines and steam turbines. Such high operating temperatures has been made possible with the development of heat-resistant super alloys forming turbine hot parts, as well as advances made in heat-resistant coating technology and cooling technology. For $15000 \mathrm{C}$ gas turbines, the adoption of single-crystal Ni-based super alloy blades and ceramic thermal barrier coatings is indispensable, and additionally steam-cooled technology should be employed. In particular, thermal barrier coating (TBC) technology is recognized as important [13].

\subsection{Wear-Resistant Ceramic Coatings for Bio implants}

Chromium oxide coatings perform particularly well in ship and stationary diesel engines where a corrosive environment is being created due to the use of less expensive but lower quality diesel fuel. Serious corrosion occurs through the impurities of the fuel such as sulfur, vanadium, sodium etc. Erosion is also of concern because due to catalytic cracking of fuel precursors $\mathrm{Al}_{2} \mathrm{O}_{3}-\mathrm{SiO}_{2}$ particles are being introduced into the diesel fuel. Thus chromia coatings are required. 


\subsection{Use of coated Mild Steel.}

$\mathrm{TiO}_{2}$ coatings possess good thermal and electrical properties and they are resistant to oxidation, corrosion, erosion and wear in high temperature environments. This property is very important factor in the applications such as pipelines, castings and automotive industry.

Table 1: SUMMARY OF THE RESEARCH CARRIED OUT ON CERAMIC COATINGS ON MILD STEEL SUBSTRATES

\begin{tabular}{|c|c|c|c|c|}
\hline Year & Substrate & Coating Material & Coating Method & Ref \\
\hline $\mathbf{2 0 1 3}$ & Mild Steel & VC - Cr7C3 & Air plasma spraying & 15 \\
\hline $\mathbf{2 0 1 2}$ & Mild Steel & YSZ & LVOA thermal spray & 16 \\
\hline $\mathbf{2 0 1 0}$ & Mild Steel & Al/SiCp & Dip Coating & 17 \\
\hline $\mathbf{2 0 0 4}$ & Mild Steel & Ni-Al2O3 & Sol - gel method & 18 \\
\hline $\mathbf{2 0 0 8}$ & Mild Steel & Alumina & Plasma spraying & 19 \\
\hline $\mathbf{1 9 9 8}$ & Mild Steel & 8YSZ & Plasma spraying & 20 \\
\hline $\mathbf{1 9 9 7}$ & Mild Steel & Alumina, Chromia & & \\
\hline
\end{tabular}

\section{CONCLUSION}

This paper gives a clear idea of current research status of advanced ceramic coatings on Mild Steel and also the work done in previous years. The following conclusions are drawn.

1. Ceramic coatings have enhanced surface properties such as roughness, hardness, wear resistance, corrosion resistance and oxidation resistance.

2. Ceramic materials surface coatings and surface modification techniques are used mainly because of its high wear resistance and low thermal conductivity.

3. Utilization of ceramic coatings with different types of fillers in casting decisively depends on theology coating properties.

4. Advanced ceramic materials namely silicon carbide is wider used as thermal barrier coating material on gas turbines and diesel engines, aircraft engines.

\section{REFERENCES}

[1] Srinivasulu K , Manisha Vidyavathy , advanced ceramic coatings on stainless steel ,a review of research, methods, materials, applications and opportunities, International Journal of Advanced Engineering Technology.

[2] Serdar salman, Ramazan Kose, Levent Urtekin, Fehim Findik, An investigation of different ceramic coatings thermal properties, Materials and Design 27 (2006) 585-590.

[3] Y. Adraider, Y. X. Pang, F. Nabhani, S. N. Hodgson, M. C. Sharp, A. Al-Waidh, Laser-induced deposition of alumina ceramic coating on stainless steel from dry thin films for surface modification, Ceramic International 40 (2014) 6151-6156.

[4] Y. Adraider, S. N. B. Hodgson, M. C. Sharp, Z. Y. Zhang, F. Nabhani, A. Al - Waidh, Y.X. Pang, Structure characterization and mechanical properties of crystalline alumina coatings on stainless steel fabricated via sol-gel technology and fibre laser processing, J. European Ceramic

Society 32 (2012) $4229-4240$.

[5] Afrooz Latifi, Mohammad Imani, Mohammad Taghi Khorasani, Morteza Daliri Joupari, Electrochemical and chemical methods for improving surface characteristics of 316L stainless steel for biomedical applications, Surface \& Coatings Technology 221 (2013) 1-12.

[6] M. Vural, S. Zeytin, A.H. Ucisik, Plasma-sprayed oxide ceramics on steel substrates, Surface and Coatings Technology 97 (1997) 347-354. 
[7] Dejiu Shen, Ming Li, Weichao Gu, Yulin Wang, Guangzhong Xing, Bo Yu, Genji Cao, Philip Nash, A novel method of preparation of metal ceramic coatings, J. Material of materials processing Technology 209 (2009) 2676-2680

[8] M. Rahman, J. Haider, T. Akter, M.S.J. Hashmi, Techniques for assessing the properties of advanced ceramic materials, Hand book of Comprehensive materials processing 1 (2014)

3- 34

[9] W B Hanson, J A Fernie, P A Sigleton, P H, Joining of metals and ceramics in turbine applications, Inst. Eng. Int. National Conference on Ceramic in Energy Applications (1994) 353 - 368.

[10] Soumendra N. Basu, Vinod K. Sarin, Thermal and Enviromental barrier coatings for Si based ceramics, J. Comprehensive Hard Materials 2 (2014) $469-489$.

[11] Kennedy D, Xue Y, Mihaylova M, Current and future application applications of surface engineering, The Engineers Journal (Technical). 59 (2005) $287-292$.

[12] High Temperature Coatings A.S.Khanna Corrosion Science \& Engineering IIT Bombay

[13] Yoshiyasu Ito, Heat resistant coating technology for gas turbines, Hand book of advanced ceramics (second edition) 10 (2) (2013) $789-806$.

[14] Zhiqiang Wang, Dianrong Gao, Friction and wear properties of stainless steel sliding against polyetheretherketone and carbon-fiber-reinforced polyetheretherketone under natural

Sea water lubrication, Materials and Design 53 (2014) 881-887.

[15] M. Farooq, S. Alam, A.Imran. B. Waseem, S. Naseem, A. Pervez, Tribological \& Wear Behavior of Yttria Stabilized Zirconia Thermal Barrier Coatings on Mild Steel, J. Pakistan Institue of Chemical Engineers, 40 (1) (2012) 21 -25.

[16] B. Torres, M.A. Garrido, A. Rico, P. Rodrigo, M. Campo, J. Rams, Wear behavior of thermal spray Al/SiCp Coatings, Wear 268 (2010) 828-836.

[17] KR. Marikkannu, K.Amutha, G.Paruthimal Kalaignan, and T. Vasudevan, studies on nickel-alumina electrocomposite coatings of over mild steel substrate(2004)

[18] G. Ruhi, O.P. Modi, A.S.K. Sinha, I.B. Singh, Effect of sintering temperatures on corrosion and wear properties of Sol-Gel alumina coatings on surface pre-treated mild steel, Corrosion Science 50 (2008) 639-649.

[19] J.S. Wallace and J. Illavsky, Elastic modulus measurements in plasma sprayed deposits, J. Thermal Spray Technology 7(4) (1998) 521-526.

[20] P.Chraska, J. Dubsky, K. Neufuss, and J. Pisacka, Alumina - Base plasma- sprayed materials part I: Phase Stability of Alumina and Alumina- Chromia, J. Thermal Spray Technology 6(3) (1997) 320 - 326. 